\title{
An African perspective on mucosal immunity and HIV-1
}

\author{
P Pala ${ }^{1}$, VR Gomez-Roman ${ }^{2}$, Gilmour ${ }^{2}$ and P Kaleebu ${ }^{1,3}$
}

HIV prevention mandates an understanding of the mechanisms of mucosal immunity with attention to some unique features of the epidemic and mucosal environment in the developing world. An effective vaccine will have to induce mucosal protection against a highly diverse virus, which is equipped with a number of immune evasion strategies. Its development will require assessment of mucosal immune responses, and it will have to protect a mucosal environment where inflammation and altered immune responses are common because of the presence of other mucosal infections, such as sexually transmitted infections and parasites, and where nutritional status may also be compromised. Ideally, not only prevention methods would protect adults but also provide cover against gastrointestinal transmission through maternal milk. Prevention might also be complemented by microbicides and circumcision, two alternative approaches to mucosal protection. It seems unlikely that a single solution will work in all instances and intervention might have to act at multiple levels and be tailored to local circumstances. We review here some of the mucosal events associated with HIV infection that are most relevant in an African setting.

\section{INTRODUCTION}

The majority of the 33 million individuals currently infected with HIV-1 live in sub-Saharan Africa. The HIV-1 epidemic in this region has some unique features compared with other settings. HIV-1 transmission in Africa is mostly through heterosexual intercourse and mother to child transmission (intrauterine, perinatal, and through breast milk) is still an issue despite availability of anti-retroviral treatment. Other routes such as parenteral-intravenous needle sharing contribute marginally, and homosexual transmission is poorly documented and probably contributing less than elsewhere. ${ }^{1-3}$

Apart from mechanical barrier methods and circumcision, the preventive arsenal does not currently contain many effective weapons. Clinical trials using treatment of sexually transmitted infections (STIs) for prevention have been disappointing. ${ }^{4}$ None of the microbicides so far tested for efficacy has yielded positive results and at least one has increased the risk of transmission through the disruption of the vaginal mucosa. ${ }^{5}$ Similarly, vaccine candidates aiming to induce humoral or cell-mediated immunity have disappointed. ${ }^{6}$

A preventive vaccine would have to induce solid mucosal immunity capable of stopping a highly diverse, rapidly evolving virus that targets some of the very effector cells of the immune system required to prevent or blunt the infection. Rational design of such a vaccine will require a thorough understanding of early transmission events at the mucosal interface as well as understanding of immune correlates of virus control in HIVinfected individuals who spontaneously control their infection. This will require development of new methods and assayswith particular attention to their suitability for vaccine trials in developing countries-to evaluate the correlates of mucosal immunogenicity and protection.

Although overall mortality is mainly affected by systemic TB co-infections, multiple pathogens are responsible for widespread background morbidity at mucosal level including genital infections and intestinal helminths. Their interactions with HIV-1 result in enhanced transmission and disease. Inflammation at mucosal sites increases the likelihood of HIV-1 acquisition and transmission. ${ }^{7}$ Prevention efforts consequently focus on understanding the mechanisms of these interactions to find ways to prevent or limit mucosal transmission. An established HIV-1 infection may in turn affect the immune response to other mucosal pathogens-human papilloma virus (HPV) infection and cervical carcinoma being an important example

\footnotetext{
${ }^{1}$ Medical Research Council-Uganda Virus Research Institute, Uganda Research Unit on AIDS, Entebbe, Uganda; ${ }^{2}$ International AIDS Vaccine Initiative, Core Laboratory, Imperial College London, London, UK; ${ }^{3}$ Uganda Virus Research Institute-International AIDS Vaccine Initiative, HIV Vaccine Program, Entebbe, Uganda. Correspondence: P Kaleebu (pontiano.kaleebu@mrcuganda.org) 
in Africa. However, we will not consider the effect of HIV-1 on other pathogens in this review.

The connection between breast-feeding and HIV-1 transmission still has particularly severe consequences in a developing country setting where safe alternatives are not available. There is uncertainty on the exact mechanism used by HIV-1 to traverse the gastrointestinal mucosal barrier of the feeding baby. A pediatric vaccine capable of inducing mucosal protection is required.

HIV-1 entry through the mucosal surfaces of the penis and urethra is less characterized than entry through cervicovaginal epithelia; however, the protective effect of circumcision is clear. For a one-time intervention that could have a significant public health impact in developing countries-comparable to a moderately effective vaccine-there is however uncertainty on the mechanism of protection and the concern that ensuing behavioral changes might negate its benefits. Understanding the foreskin route of infection could guide decisions for large-scale interventions.

Microbicides aim to block HIV transmission through antiviral agents and/or enhancement of non-specific immunity mechanisms at the genital mucosa level. Their basic mechanisms of interference with viral entry could be a robust approach to the extreme viral diversity encountered in the African continent.

In this review, we will consider those aspects of mucosal immunology that are particularly relevant to control of HIV-1 in Africa and the developing world. The approach is multi-faceted because it is unlikely that a single type of intervention could achieve maximal control.

\section{MUCOSALTRANSMISSION}

Mucosal surfaces of the genital and intestinal systems are the entry point of most HIV-1 infections (reviewed by Hladik and McElrath ${ }^{8}$ ). The immunological subsystem of the gut and the lower genital tract is subsequently the main target organ for HIV-1 pathology (recently reviewed by Brenchley and Douek ${ }^{9}$ ). In simian immunodeficiency virus (SIV)-infected macaques the virus establishes foci of infection in the submucosa within 60 min of contacting the vaginal mucosa, ${ }^{10}$ rapidly disseminates to the local draining lymph nodes and is detected systemically 6-25 days later. ${ }^{11,12}$ Although HIV-1 can traverse epithelial cells and dendritic cells (DCs), ${ }^{13-16}$ the first cells to become productively infected are probably the CCR $5^{+} \mathrm{CD} 4{ }^{+} \mathrm{T}$ cells, DC, and macrophages; DCs and T-cell clusters then drive the infection, and DCs migrating to lymph nodes facilitate the dissemination of the virus and destruction of $30-60 \%$ of $\mathrm{CD} 4^{+}$memory cells throughout the body within a few days, particularly in mucosal compartments, the most affected being the gut. ${ }^{17}$ The $\mathrm{SIV} /$ macaque model further highlighted that both resting and activated $\mathrm{CD} 4{ }^{+} \mathrm{T}$ cells are susceptible to infection ${ }^{18}$ and that gut pathology in early infection includes apoptosis of epithelial cells in the small and large intestine. ${ }^{19}$

HIV-1 transmission has features of limiting dilution cloning: in a study of acute infection in HIV-1 discordant couples in $Z_{\text {ambia }}{ }^{20}$ it was shown that one or two viruses establish the infection despite exposure to a heterogeneous quasi-species, a finding that has been confirmed. ${ }^{21,22}$ This transmission bottleneck would appear to be at the mucosal surface ${ }^{7}$ and could be a major opportunity for protective interventions.

\section{DESIGN AND ASSESSMENT OF AN EFFECTIVE PREVENTIVE HIV-1 VACCINE}

The need for a safe, effective, preventive HIV-1 vaccine, as part of a comprehensive prevention package, is compelling. Although strides have been made in treatment and prevention programs these have yet to have an impact on transmission rates, particularly in Africa where the medical infrastructure to provide lifelong chemotherapy and follow-up simply does not exist in the majority of countries. HIV-1 represents a unique combination of formidable challenges to vaccinologists (Table 1). ${ }^{23-25}$ Of particular note in Africa is the tremendous sequence diversity and rapid virus evolution. Currently, 39 various preventive AIDS vaccines are being tested in human trials. Of these, 17 are being tested in developing countries (http://www.iavireport.org/specials/OngoingTrialsofPreventiveHIVVaccines. pdf). Although the end points for phase 1 (vaccine safety) and phase 3 (vaccine efficacy) trials are relatively straightforward to measure, the end points for phase 2 vaccine immunogenicity trials are proving challenging to define with certainty. Although definitive correlates of protection will remain elusive until a vaccine candidate shows some level of efficacy in the clinic, protection, or containment of the virus within the mucosa or draining lymph nodes is only likely to be achieved if both antibodies and T cells capable of recognizing a broad spectrum of viruses are induced at the local site of infection. Potent systemic anti-viral CD8 ${ }^{+} \mathrm{T}$ cells and antibodies, particularly, in mucosal tissues such as in the gut, may also have an impact on virus replication and disease progression should infection occur. Three trials with efficacy end points have been conducted to date, and all failed; the first two used an antibody inducing gp120 candidate and the third a T-cell inducing, recombinant adeno5 viral vector: the gp120 candidate failed to induce broadly cross-reactive-neutralizing antibodies and the adeno- 5 failed to induce a broad T-cell response. The design of an immunogen capable of inducing potent broadly cross-reactive antibodies has proved to be a formidable scientific challenge. ${ }^{26}$ The recent failure of the MRKAd5 HIV-1 Gag/Pol/Nef candidate vaccine to either protect from disease acquisition or progression has shown that elicitation of systemic T-cell immunity, with limited breadth as measured with the interferon (IFN- $\gamma$ ) enzyme linked immuno spot assay, is not sufficient to confer protection against a mucosally acquired HIV-1 infection in men. ${ }^{27}$ Although mucosal immunity was not directly evaluated, a trend toward an increased number of HIV-1 infections was observed in uncircumcised vaccine recipients, ${ }^{6,28}$ suggesting that either no protective responses or even detrimental responses might have been induced in the foreskin. The majority of T-cell vaccine candidates have not been designed specifically to induce mucosal T-cell responses ${ }^{29}$ and with very few exceptions vaccines are being administered parentally, with immunogenicity assessments and conclusions being drawn from peripheral blood samples in nearly all vaccine trials to date. 


\section{Table 1 Challenges in the development of an HIV-1 vaccine}

\begin{tabular}{|c|c|}
\hline \multicolumn{2}{|l|}{ Challenge } \\
\hline Sequence diversity & $\begin{array}{l}\text { Rapid mutation rate, RNA } \\
\text { genome highly mutatable and } \\
\text { RT error prone, immune selec- } \\
\text { tion pressure, recombination }\end{array}$ \\
\hline \multicolumn{2}{|l|}{$\begin{array}{l}\text { Integration of viral genome } \\
\text { establishes latent viral pool }\end{array}$} \\
\hline \multicolumn{2}{|l|}{ No small animal model } \\
\hline \multicolumn{2}{|l|}{$\begin{array}{l}\text { Correlates of protection } \\
\text { unknown }\end{array}$} \\
\hline Mucosal transmission & $\begin{array}{l}\text { Mucosal immune system com- } \\
\text { partmentalized and will require } \\
\text { protection at multiple mucosal } \\
\text { surface }\end{array}$ \\
\hline $\begin{array}{l}\text { Immune destruction in mucosal } \\
\text { tissues, most notably the gut }\end{array}$ & $\begin{array}{l}\text { Rapid T-cell depletion in } \\
\text { mucosal tissues, immune dys- } \\
\text { regulation }\end{array}$ \\
\hline \multirow[t]{2}{*}{$\begin{array}{l}\text { Immune evasion of antibody } \\
\text { and T-cell responses }\end{array}$} & $\begin{array}{l}\text { Broadly cross-reactive neutral- } \\
\text { izing antibody is rarely pro- } \\
\text { duced because of masking of } \\
\text { key epitopes }\end{array}$ \\
\hline & $\begin{array}{l}\text { T-cell epitopes readily mutate } \\
\text { and escape T-cell response, } \\
\text { HIV-1 proteins modulate the } \\
\text { host immune response }\end{array}$ \\
\hline $\begin{array}{l}\text { Assessing mucosal immune } \\
\text { responses }\end{array}$ & \\
\hline
\end{tabular}

Clearly, mucosal correlates of protection need to be better defined and novel mucosal immunogenicity assays need to be implemented as part of vaccine evaluation and development. Vaccine discovery and development need to focus on strategies that may specifically induce mucosal immunity. These are among the priorities for mucosal immunity research recently proposed by the Global HIV-1 Vaccine Enterprise. ${ }^{30}$

\section{ADDRESSING THE NEUTRALIZING ANTIBODY PROBLEM USING MUCOSAL SPECIMENS FROM DEVELOPING COUNTRIES AND A REPERTOIRE OF ASSAYS}

For the purposes of standardization and high throughput, current assays to assess HIV-neutralizing antibodies use sera and cells such as the TZM-bl cell line, an epithelial, HeLaderived cell line expressing artificially high levels of CCR5, or in peripheral blood mononuclear cell-based HIV-1-neutralization assays. ${ }^{31}$ Thus, our knowledge of HIV-1-neutralizing antibody biology is still limited to the context of non-mucosal cells and non-mucosal fluids. It was recently shown that the broadly neutralizing antibodies 2F5, 2G12, and IgG1b12 lack the ability to inhibit transcytosis of cell-free and cell-associated HIV-1 across a tight monolayer of human endometrial carcinoma-1 cells. In contrast, IgG and S-IgA purified from colostrum samples collected from four HIV-infected women in Bangui (Central African Republic) were able to inhibit transcytosis of the X4-tropic HIV-LAI strain. ${ }^{32}$ This suggests conventional HIV-1 neutralization and transcytosis, across a mucosal cell layer, are two distinct mechanisms and it remains to be established which of the two will be more relevant in the context of a mucosal HIV-1 vaccine.

Rare and broadly neutralizing monoclonal antibodies such as 2 F5, 2G12, and $4 \mathrm{E} 10$ have been isolated from the blood of clade-B HIV-1-infected patients. These antibodies are often used as the gold standards for the broad neutralization profile that one would desire to elicit with an HIV-1 vaccine. However, it is still unclear whether these antibodies can effectively neutralize a broad panel of HIV-1 strains isolated from semen and cervicovaginal fluids collected from developing countries. Panels of viruses representing founder viruses from around the world are beginning to be established, but there is yet to be a standard panel of HIV-1 strains purely derived from mucosal fluids. Conversely, broadly neutralizing monoclonal antibodies have not been isolated from mucosal compartments of nonclade-B HIV-1-infected individuals. Efforts are now underway to indentify novel broadly neutralizing monoclonal antibodies from multiple clades and countries. ${ }^{33}$

It is also worth noting that sIgA plasma cells are found in mucosal tissues and humans secrete gram quantities of $\operatorname{sg} \mathrm{A}$ each day, making sIgA the most abundant immunoglobulin class in secretions, and undoubtedly important (reviewed by Macpherson et al. ${ }^{34}$ ). Although IgG antibodies transudate across mucosal surfaces and have certainly conferred protection against cervical cancer in the case of HPV vaccination, ${ }^{35}$ they are rapidly degraded and unlike sIgA are also affected by the menstrual cycle, ${ }^{36}$ which may have an impact on efficacy over time. Nonneutralizing sIgA could also have an impact on transmission by (a) immune exclusion (cross-linking and entrapment in mucus) to prevent adherence, (b) antibody-dependent cellular cytotoxicity destruction of infected cells, (c) blocking transcytosis, and (d) mediating transport back across the epithelial barrier by the polymeric immunoglobulin receptor. Neutralizing IgAs have also been shown to prevent R5 HIV-1 infection of both CD4 ${ }^{+}$ T cells and macrophages. ${ }^{37}$ The role of mucosal IgA vs. serum IgG in HIV-exposed, persistently uninfected individuals was reviewed by Alexander and Mestecky. ${ }^{38}$ Conversion of the 2F5 IgG monoclonal antibody into an IgA Fab increased its neutralizing potency and conferred the antibody with trancytosis-blocking activity, ${ }^{39}$ suggesting that vaccine-induced $\operatorname{IgA}$ may have a more potent effect than IgG alone. To induce IgA, vaccines must be delivered through the mucosal route, for example mucosal delivery of HPV vaccine did induce IgA responses ${ }^{40}$ and failure of candidate HIV-1 vaccine to elicit IgA thus far can be attributed to the almost exclusive use of parenteral vaccinations.

Other types of non-conventional HIV-1 neutralization in mucosal compartments could be examined in more detail. This would include mucosal antibody-dependent cellular cytotoxicity of HIV-infected cells, the lysis and opsonization of antibody-coated HIV-infected cells by complement deposition in the mucosa and the inhibition of HIV-1 infection mediated by natural antibodies (Nabs). For example, healthy and HIVinfected women in Bangui were recently shown to have natural anti-CCR5 antibodies in sera, breast milk, and cervicovaginal lavage. These natural antibodies have the capacity to inhibit the infection of macrophages and DCs with R5-tropic HIV-1 
strains. Natural antibodies also have the capacity to inhibit the transfer of R5-tropic HIV-1 from DCs to T cells. ${ }^{41}$ Harnessing the activity of natural antibodies present in mucosal secretions may prove to be beneficial in the development of microbicides and vaccines.

\section{T-CELL ISSUES AND MUCOSAL VACCINE DEVELOPMENT}

Probably the most significant challenge to developing effective $\mathrm{CD}^{+}{ }^{+} \mathrm{T}$-cell immunogens-particularly in Africa-is the incredible sequence diversity of the virus, its ability to recombine, and its rapid escape under immune selection pressure. This is coupled with the need to have these cells present in the mucosal tissue at the time of exposure to contain the infection locally, or in the gut shortly, thereafter to impact viremia and disease progression. ${ }^{42}$ Efforts are now starting to focus on the design of T-cell immunogens based on highly conserved regions of the viruses mosaic, ancestral, or conserved sequences ${ }^{43-45}$ that might induce responses to a broad and diverse range of viruses. ${ }^{42} \mathrm{~T}$-cell assays used in vaccine trials and HIV-1 pathogenesis studies often rely on the use of high concentrations of exogenously added peptides bypassing natural antigen processing pathways, and measuring both high and low avidity cells, or irrelevant target cells such as B cells. Not all T-cell epitopes are equivalent, and not all $\mathrm{T}$ cells will have potent or broad antiviral activity. ELISPOT, flow cytometry, or tetramer assays are akin to binding antibody assays; however, the 1st generation of T-cell neutralization assays ${ }^{25}$ for use in HIV-1 vaccine trials, using replication competent panels of viruses and autologous target cells, are in qualification stages. They correlate with in vivo virus control in HIV-1-infected individuals and show excellent specificity and precision in vaccines (Gilmour et al., unpublished).

\section{DELIVERY ROUTES}

Mucosal vaccine development presents a unique set of challenges and issues. The mucosal immune system is highly compartmentalized and the administration route, adjuvant and antigen delivery system may be as important as the immunogen design itself. This has been extensively reviewed recently. ${ }^{31,46-48}$ A central role of certain mucosal immune compartments such as the gastrointestinal tract is to induce tolerance, which may make induction of mucosal immune responses through these routes challenging. However, it is also becoming apparent that to elicit specific mucosal immune responses priming may need to be through a mucosal surface (reviewed in refs. ${ }^{46,47,49}$ ).

Oral vaccination has proved effective with a number of vaccines including live polio, inactivated oral cholera, live typhoid fever, and rotavirus. These vaccines have tropism for cells in the intestine, and induce good antibody and T-cell responses both systemically and in the upper intestine, but not in the lower intestine or reproductive tract. Common nutritional deficiencies and intestinal infections such as helminths may significantly alter the effectiveness of oral vaccination in Africa.

Rectal immunization has resulted in rectal, lower intestinal, and systemic immune responses without significant responses in the genital tract. Rectal immunization of macaques induces anti-viral T cells in the rectal mucosa and induction of protective immunity after rectal challenge with pathogenic simian human immunodeficiency virus- $1.50,51$

Mechanisms of immune induction in the male and female genital tract are poorly understood. M cells or organized lymphoid follicles have not been identified. Local immunization in the vagina with replicating and non-replicating vaccine antigens in mice ${ }^{52}$ non human primate ${ }^{53}$ and humans $s^{54-56}$ induces local $\mathrm{CD}^{+} \mathrm{T}$ cell, IgG, and IgA responses and could be affected by the menstrual cycle. ${ }^{56}$ Very little is known about vaccination of the male urethra and penile foreskin; however, the majority of men in Africa will be infected through this route. Significant gender differences in mucosal immunity and vaccine efficacy might exist, as suggested by a phase 3 herpes simplex type- 2 (HSV-2) vaccine trial ${ }^{57}$ where protection could be achieved in $74 \%$ of seronegative women but $0 \%$ of men or HSV-1 seropositive women. For this reason it will be essential that vaccine candidates be tested in trials enrolling both men and women.

Intranasal (IN) vaccination offers an attractive route of vaccine administration and resulted in good antibody and T-cell responses in the female genital tract, urethra, saliva, intestine systemically, but not in the rectum. Responses in the female genital tract following intranasal immunization were better than after systemic immunization, required $1 / 10$ the dose and aerosolization may not be required. ${ }^{58,59}$ Perhaps an optimal regimen might have to consider priming both intranasally and rectally, followed by systemic boosting.

Low-absorption efficiency at mucosal surfaces and suboptimal mucosal immune responses have often meant mucosal adjuvants are required. ${ }^{60}$ There has been a growing trend in vaccine development toward non-replicating vaccine modalities for safety reasons; however, the efficacy of live-attenuated SIV in non-human primates is consistent with the efficacy observed with some of the most successful vaccines licensed against viral infections (measles, polio, mumps, rubella), which are all liveattenuated vaccines. Given the unacceptable safety concerns with an attenuated replication competent HIV-1 vaccine, an alternative strategy might be intranasal delivery of a mucosal tropic, replication competent vector carrying the HIV-1 target antigens. This strategy is likely to overcome the need for adjuvants and could also provide similar activation of the inflammasome and innate pathways thought to be required for an effective vaccine. ${ }^{61}$ This is a strategy being pursued by the IAVI and DNAVec using the Sendai vector. ${ }^{62,63}$

\section{MUCOSAL ASSAY DEVELOPMENT AND IMPLEMENTION}

Low cell yields and the need for frequent and reliable access to mucosal samples are the major hurdles to developing robust and relevant mucosal assays. Methods to assess T cells and antibody responses in blood in HIV-1 vaccine trials have been implemented according to good clinical laboratory practice across Africa $^{64,65}$ and a number of centers have also expert flow-cytometry facilities. In preparation for HIV-1 vaccine immunogenicity trials using cervical specimens, methods are being developed in many countries using cervical cytobrushes from HIV-negative and HIV-positive women. A cervical cytobrush yields an average 
Table 2 Methods to collect mucosal specimens for immunogenicity studies and HIV-1 vaccine trials

\begin{tabular}{|c|c|c|c|c|c|}
\hline Collection device & Collection method & $\begin{array}{l}\text { Mucosal sites that } \\
\text { can be accessed }\end{array}$ & $\begin{array}{l}\text { Mucosal specimens } \\
\text { that can be } \\
\text { collected }\end{array}$ & Advantages & Disadvantages \\
\hline $\begin{array}{l}\text { Digene cervical } \\
\text { brush }\end{array}$ & Speculum examination & $\begin{array}{l}\text { Cervix } \\
\text { Rectum }\end{array}$ & $\begin{array}{l}\text { Cellular material } \\
\text { from cervical os }\end{array}$ & $\begin{array}{l}\text { Provides material } \\
\text { for cellular assays }\end{array}$ & $\begin{array}{l}\text { Limited sample } \\
\text { volume } \\
\text { Cannot be self- } \\
\text { administered }\end{array}$ \\
\hline Cytobrush & Speculum examination & $\begin{array}{l}\text { Cervix } \\
\text { Rectum }\end{array}$ & $\begin{array}{l}\text { Cells lining the } \\
\text { rectal epithelium }\end{array}$ & & \\
\hline Tampon & Insertion for 10 min & $\begin{array}{l}\text { Cervix } \\
\text { Rectum }\end{array}$ & $\begin{array}{l}\text { Primarily cell-free } \\
\text { material (secreted } \\
\text { antibody and local } \\
\text { cytokines) }\end{array}$ & $\begin{array}{l}\text { Can be self-col- } \\
\text { lected } \\
\text { Non-invasive }\end{array}$ & $\begin{array}{l}\text { Small sample } \\
\text { volume }\end{array}$ \\
\hline Swab & $\begin{array}{l}\text { Self-collection by } \\
\text { swirling }\end{array}$ & $\begin{array}{l}\text { Cervix } \\
\text { Rectum }\end{array}$ & & & \\
\hline $\begin{array}{l}\text { Absorption } \\
\text { wicks, including } \\
\text { the Sno Strip fil- } \\
\text { ter-paper wicks }\end{array}$ & $\begin{array}{l}\text { Speculum examination } \\
\text { followed by insertion } \\
\text { of paper wick into } \\
\text { endocervix }\end{array}$ & Endocervix & $\begin{array}{l}\text { Primarily cell-free } \\
\text { material (antibod- } \\
\text { ies, local cytokines } \\
\text { and HIV-1 shed at } \\
\text { the cervix) }\end{array}$ & $\begin{array}{l}\text { Precision of } \\
\text { mucosal site from } \\
\text { which sample is } \\
\text { being collected } \\
\text { Allows for stand- } \\
\text { ardization of HIV-1 } \\
\text { viral load measure- } \\
\text { ments }\end{array}$ & $\begin{array}{l}\text { Cannot be self- } \\
\text { administered }\end{array}$ \\
\hline $\begin{array}{l}\text { Ophthalmic } \\
\text { sponges, includ- } \\
\text { ing the Weck-Cel, } \\
\text { Ultracell, and } \\
\text { Merocel sponges }\end{array}$ & $\begin{array}{l}\text { Adapted ophthalmic } \\
\text { fluid collection devices }\end{array}$ & $\begin{array}{l}\text { Cervix } \\
\text { Rectum }\end{array}$ & $\begin{array}{l}\text { Primarily cell-free } \\
\text { material (antibodies } \\
\text { and local cytokines) }\end{array}$ & $\begin{array}{l}\text { Allows for non-trau- } \\
\text { matic collection of } \\
\text { cervical and rectal } \\
\text { secretions }\end{array}$ & $\begin{array}{l}\text { Small sample } \\
\text { volume }\end{array}$ \\
\hline
\end{tabular}

Gl, gastrointestinal

of half a million mucosal mononuclear cells that can be directly stimulated with HIV-1 peptides to assess production of multiple cytokines by flow cytometry. Thus, Gag-specific cervical T-cell responses have been assessed in women attending community clinics in Cape Town, South Africa. ${ }^{66}$ Genital responses did not correlate with those detected in blood and T-cell yields were often low in the absence of inflammation. Systems biology approaches requiring low cell numbers, such as micro-arrays, are becoming more robust and affordable, and could become part of a comprehensive immune monitoring panel in vaccine trials for both blood and mucosal tissues. ${ }^{61}$ However, given the complex bio-informatics associated with such approaches, collaboration with partners outside Africa will be required initially.

Table 2 outlines a number of non-invasive methods commonly used for collecting mucosal secretions. The absorbent Weck-Cel (Medtronic Xomed, Jacksonville, FL) sponge appears to be more reproducible and effective than lavage.${ }^{67}$ Such non- invasive sampling could be deployed relatively easily at HIV-1 vaccine trial sites and research centers in Africa, where many teams routinely carry out smear tests and have taken part in microbicide trials. Genital fluids can also be used in relatively simple assays to assess mucosal antibodies, viral RNA or p24 antigen, and multiple cytokines. Collection of secretions from the female reproductive tract could be implemented in HIV1 vaccine trials; however, the feasibility of sampling the male genital tract and rectum needs to be addressed also.

The gut is the initial site of HIV-1 replication and massive $\mathrm{CD} 4^{+} \mathrm{T}$-cell depletion irrespective of the transmission route. It is conceivable, therefore, that an efficacious HIV-1 vaccine could be one that prevents high-level virus replication and $\mathrm{CD} 4^{+} \mathrm{T}$ cell depletion in the gut during this so-called initial "window" of opportunity. One would expect HIV-specific CD8 ${ }^{+} \mathrm{T}$ cells residing in the gut with potent and broadly cross-reactive anti-viral responses to control viral replication. Their elicitation during 
vaccination is, therefore, highly desirable. Consistent with this hypothesis, the magnitude and the complexity of rectal HIV-1 gag-specific gut $\mathrm{CD} 8^{+} \mathrm{T}$-cell responses were shown to correlate with lower viral loads and with elite-controller clinical status in subtype-B, chronically infected cohorts in the United States. ${ }^{68,69}$ A major challenge to HIV vaccinologists will be to elicit and assess such a potentially protective response in the gut.

In a recent phase 1 safety and immunogenicity trial using the vaccinia-based TBC-3B HIV-1 vaccine given subcutaneously, participants consented to donating rectal biopsies by undergoing flexible sigmoidoscopy. Expanded cells did not produce significant levels of IFN- $\gamma$ on stimulation with HIV-1 peptides. ${ }^{70}$ This study shows that invasive sampling can be performed in phase 1 studies; however, this vaccine delivered intramuscularly did not induce rectal responses.

Would gut sampling be ethical and feasible across HIV-1 vaccine clinical trial sites in the developing world? In terms of safety, rectal and colonic biopsies are considered invasive and may pose a minor risk of colon perforation to the patient, making them relatively unappealing for wide use. Tearing the rectal lining during flexible sigmoidoscopy could also increase the risk of the donor to rectally acquired HIV-1 infection, raising ethical concerns about its feasibility in clinical trials with volunteers who may be at risk of HIV-1 exposure through the same surface. Assessment of T-cell responses from mucosal tissues (reproductive tract and gut) should become part of the immunogenicity assessment in early product development through small phase 1 studies, with volunteers who are at very low risk of HIV-1 acquisition.

\section{GENITAL INFECTIONS}

STIs are among the most common reasons for seeking medical care in many parts of Africa and other developing world and their contribution to HIV-1 infection has been shown in many studies (reviewed in ref. ${ }^{71}$ ). The non-specific or innate immune mechanisms, which include the skin, secretions, opsonins and phagocytes, are important first lines of defence. ${ }^{72}$ In fact an intact genital epithelium is an effective barrier, infections that disrupt the mucosal surfaces i.e., the genital ulcerative diseases and non-ulcerative STIs that cause inflammation can greatly increase the chances of HIV-1 infection (reviewed in ref. ${ }^{73}$ ) and facilitate infection by multiple genetic variants, ${ }^{74}$ relieving the transmission bottleneck ${ }^{7}$ and-presumably-ultimately accelerating viral evolution through recombination.

Genital ulcerative and non-ulcerative infections cause inflammatory cell infiltration at the mucosal site of infection, and hence increase the number of potential target cells for HIV-1 infection. ${ }^{75}$ DCs in the normal uninfected genital mucosa reside immediately beneath the epithelium, i.e., the Langerhans cells and in the submucosa (submucosal DCs). ${ }^{76}$ However, during infections or inflammations, additional myeloid DCs and IFN- $\alpha$-producing plasmacytoid DCs are recruited from the peripheral blood. The role of DCs in HIV-1 transmission has been recently reviewed. ${ }^{77}$ As pro-inflammatory cytokines and chemokines are produced locally, more macrophages, and later $\mathrm{CD}^{+}{ }^{+}$and $\mathrm{CD} 8{ }^{+} \mathrm{T}$ cells are recruited. ${ }^{78,79}$ There is, as a result, an increase in $\mathrm{DC}^{-S I G N}{ }^{+} \mathrm{DC}$ and CCR $5^{+}$
$\mathrm{CD} 4{ }^{+} \mathrm{T}$ cells, which are targets for HIV-1. These early events have been reviewed. ${ }^{80}$

Table 3 summarizes the features of common mucosal infections that influence HIV acquisition in Africa.

\section{HERPES SIMPLEX TYPE 2}

HSV-2 is the leading cause of genital ulcerative diseases in both developing and developed countries, ${ }^{81}$ with nearly $90 \%$ prevalence in HIV-1-positive persons. It is believed that HSV-2 plays a major role in the spread of $\mathrm{HIV}-1^{82}$ increasing the infectiousness of an HIV-1-positive person through increased HIV-1 shedding, ${ }^{83,84}$ viral replication ${ }^{85,86}$ and increasing acquisition in the HIV-1 uninfected people. A recent analysis of data from a male circumcision trial in Orange Farm, South Africa reported a population fraction of incident HIV infection attributable to HSV-2 of $27.8 \% .{ }^{87}$ The possible mechanisms of how HSV-2 can lead to increased acquisition of HIV-1 include not only disruption of the mucosal membrane, but also HSV-2 has been implicated in the increase in the HIV-1 target cells in the genital mucosa as described above and transactivation of the HIV-1 long terminal repeat in vitro. ${ }^{88}$

HIV-1 prevention strategies would therefore include treatment of HSV-2. Unfortunately, the results of clinical trials using treatment of HSV-2 for prevention have been disappointing. ${ }^{89-92}$ HSV-2 suppressive therapy with valacyclovir or acyclovir can lower the HIV-1 viral load in the blood, rectal secretions, ${ }^{93}$ and seminal fluid ${ }^{94}$ of HIV-1 and HSV-2 co-infected men and genital shedding in women, ${ }^{95}$ which might have a public health benefit of limiting transmission as well as improving HIV-1 suppression in the infected individual. Conversely, two recent trials reported no efficacy of HSV-2 suppressive therapy on reducing HIV-1 acquisition. ${ }^{4,96}$ The reasons for this failure are not yet clear but taken together these results suggest that HSV-2 suppressive therapy might be more effective in reducing shedding from HSV-2/HIV-1 co-infected individuals than in preventing HIV-1 acquisition in HSV-2-infected individuals.

The effect of HSV-2 in modulating mucosal responses and HIV-1 transmission will have to be considered in the evaluation of future mucosal vaccines.

\section{GONORRHOEA}

Non-ulcerative STIs such as Neisseria gonorrhoeae (NG) and Chlamydia trachomatis infections may also recruit and activate HIV-susceptible cells as described above. ${ }^{75,97}$ Genital infections can also influence the adaptive immune responses. The interaction between gonorrhoea and HIV-1 goes in opposite directions depending on the stage of infection. In heterosexual HIV-1 acquisition, genital Neisseria gonorrhoeae has recently been associated with enhanced HIV-1-specific CD8 ${ }^{+}$T-cell responses though not with differences in viral load set point. ${ }^{98}$ However, in chronic HIV-1 infection, incident infection with Neisseria gonorrhoeae was associated with transient increases in blood HIV-1 viral load and decreased absolute CD4 ${ }^{+}$ T-cell counts, ${ }^{99}$ an effect that might be related to impairment of HIV-1-specific CD8 ${ }^{+}$T-cell responses ${ }^{100}$ and CD $4^{+}$T-cell function. ${ }^{101}$ Neisseria gonorrhoeae has also been shown to 
Table 3 Common genital diseases in Africa and their effect on HIV-1 acquisition

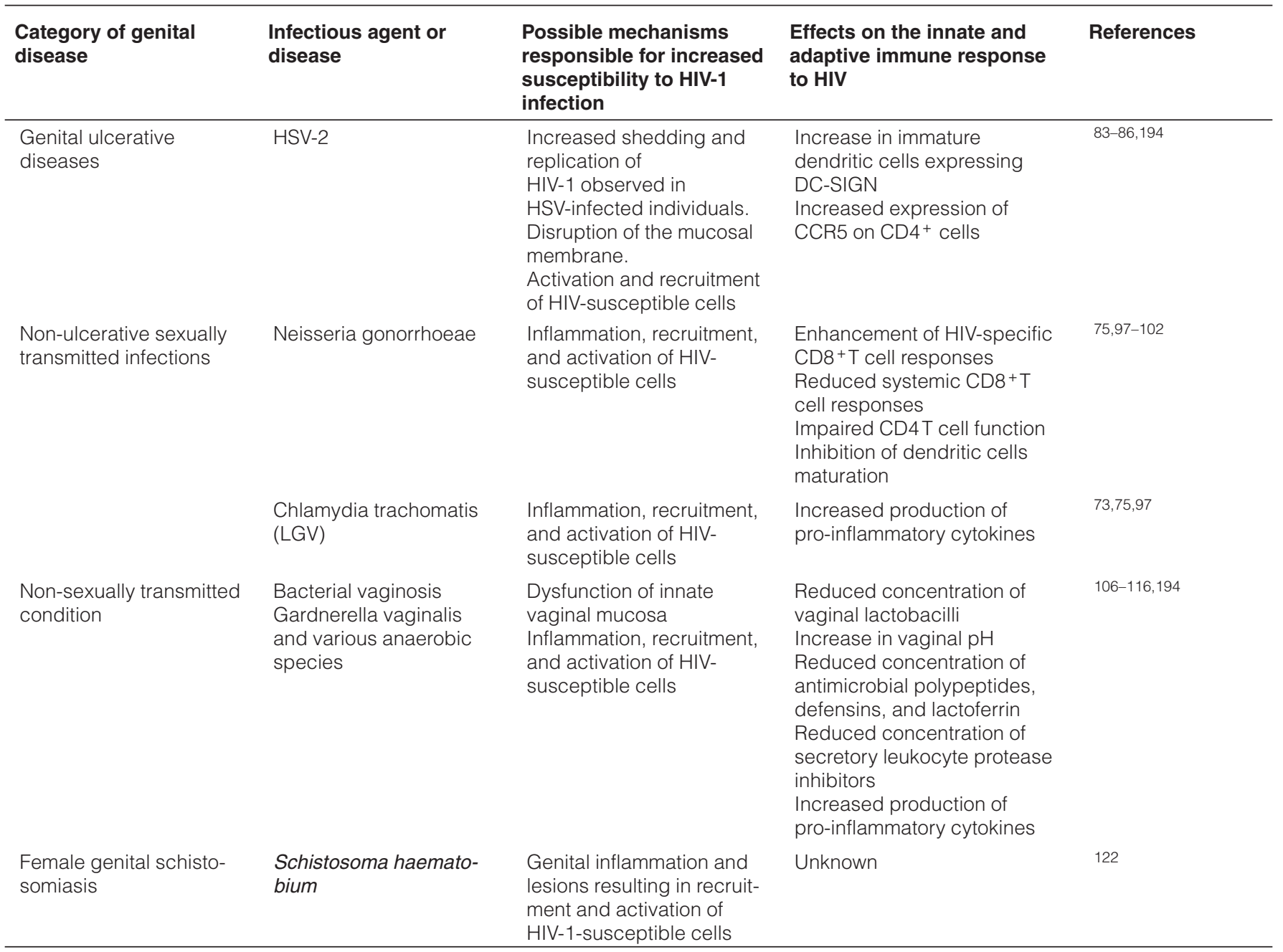

inhibit maturation of DCs and their ability to prime HIVspecific immune responses. ${ }^{102}$ Whether these events start by modulating the innate and adaptive responses at the mucosal level is not clear as gonococcal lipo-oligosaccharide can induce anti-HIV-1 innate immunity in primary human macrophages through IFN- $\beta$ release induced by toll-like receptor- 4 signaling. ${ }^{103}$ The related N. meningitides polysaccharides are now being developed for use as adjuvants in mucosal vaccine research. ${ }^{104,105}$

\section{BACTERIAL VAGINOSIS}

Bacterial vaginosis (BV), a non-sexually transmitted condition, has been associated with increased risk of HIV-1 acquisition ${ }^{106,107}$ possibly through a dysfunction in the innate immunity of the vaginal mucosa. ${ }^{108} \mathrm{BV}$ results from the abnormal outgrowth of several species of anaerobic bacteria outcompeting the normal vaginal lactobacilli flora and resulting in an elevation of vaginal fluid $\mathrm{pH}$. Cervical lavage fluid from women with BV was found to be deficient in antimicrobial polypeptides such as lysozymes, lactoferrins, defensins, and in antibacterial activity compared with healthy women or other infections ${ }^{109}$ though the mechanism was unclear. These polypeptides are small, amphiphilic cationic molecules with broad-spectrum activity against bacteria, fungi, and virus and are increasingly considered to be major effectors of the innate immune system. ${ }^{110}$ Others have also indicated a reduction in secretory leukocyte protease inhibitors (SLPIs) in women with BV and other STIs. These antimicrobial peptides and proteins have been shown to have some effect on HIV-1 $1^{108,111,112}$ contributing to the innate host defense of the vagina. ${ }^{113}$ Although the association between the SLPI levels and reduced sexual HIV-1 acquisition is less clear, higher SPLI concentrations in vaginal secretions have been correlated with reduced perinatal transmission. ${ }^{114}$ SLPIs have in vitro anti-HIV-1 activity by blocking macrophage infection at physiological concentrations ${ }^{115}$ possibly through interaction with annexin-II. ${ }^{116}$

Similar to HSV-2 and other STIs, BV recruits inflammatory cells to the vaginal mucosa. Pro-inflammatory cytokines such as interleukin-1- $\beta$ (IL-1- $\beta$ ) and tumor necrosis factor- $\alpha$, which can upregulate HIV-1 in vitro, are increased in genital secretions during BV infection. ${ }^{117}$ Vaginal lavage fluids of women with BV were also found with low neutrophil-attracting chemokine IL-8 
and $\beta$-defensins, ${ }^{109}$ whereas others found increased IL-8 and pro-inflammatory chemokines but not neutrophils. ${ }^{118,119}$ Other mechanisms for synergy between BV and HIV-1 include stimulation of HIV-1 expression through toll-like receptor-2 receptors (reviewed in ref. ${ }^{120}$ ) or effects on HIV-1 uptake and processing by DCs. ${ }^{119} \mathrm{BV}$ can induce IL-12, IL-23, and p40 secretion and induce activation markers CD40, CD83, CD86, and HLA-DR on DCs; however, the enhancement of HIV-1 infection is not mediated by trans-infection. ${ }^{119}$

\section{HELMINTHS}

Helminths have been implicated in impairment of the immune response to HIV-1 leading to greater susceptibility to HIV-1 acquisition and more rapid HIV-1 progression (review in ref. ${ }^{121}$ ). This hypothesis was based on the concept that a T helper-2 (Th2) bias induced by helminths could be detrimental by suppressing protective Th1 responses to HIV-1 and expanding Th2 lymphocytes considered more susceptible to HIV-1 infection; also the immune activation might increase HIV-1 co-receptor expression on susceptible cells.

Early observations gave inconclusive results regarding associations between helminth infection and susceptibility to HIV-1 or HIV-1 disease progression. Cross-sectional studies of co-infection are handicapped by confounding factors and intervention studies have been hampered by ethical issues around withholding anti-helminths. No studies have directly addressed the effects of helminths on susceptibility to HIV-1 infection or effects of helminths on HIV-1 incidence except in the special case of female genital schistosomiasis, where genital inflammation and lesions are associated with increased risk of HIV-1 infection. ${ }^{122}$ There is, however, one study in rhesus macaques where acute schistosoma mansoni infection was associated with susceptibility to systemic SHIV-1 clade$\mathrm{C}$ infection after mucosal virus exposure. ${ }^{123}$ Although several studies have shown in patients and experimental animal models that helminth infections significantly impair Th1-type vaccine-specific immune responses to bacterial and viral vaccines, ${ }^{124-129}$ it is only recently that the effect on HIV-1 vaccines was also shown in a mice model, where HIV-1 DNA T-cell responses were suppressed in mice infected with human helminth schistosoma mansoni compared with controls with no such infection. ${ }^{130}$

Understanding the impact of helminths on vaccinations through modulation of innate and adaptive, systemic, and mucosal immune responses remains essential for the developing world, where co-infestations are common. A few phase $1 \mathrm{~b}$ studies are planned in East Africa to investigate the impact of worm infections on Malaria, TB, and HIV1 vaccine immunogenicity (Giuseppe Pantaleo, personal communication).

\section{BREAST-FEEDING}

Transmission of HIV-1 through the oral route has been difficult to ascertain in adults engaging in oral sex, because of the frequent coincidence of multiple risky sexual practices (reviewed in ref. ${ }^{131}$ ). Despite the effectiveness of antiretroviral treatment administered perinatally to mother and baby, in sub-Saharan Africa the late postnatal transmission by breast-feeding HIV-1 ${ }^{+}$ mothers to a suckling baby was about $6.9 \%$ (excluding seroconversions occurring in the first six weeks after birth. Overall transmission rate at 12 months was 20.4\%). ${ }^{132}$ In developed countries, transmission is simply avoided by replacement of breast milk feeding with artificial formula milk but this approach is problematic in sub-Saharan Africa, where risks associated with formula milk feeding without adequate safe water provisions outweigh those of HIV-1 transmission. In addition, formula feeding may be viewed as a hallmark for HIV-1 infection and lead to social stigmatization, discrimination, and even violence and abandonment of the woman and her infant. The WHO recommends that HIV-1-infected mothers should breast-feed if safe formula milk feeding is not possible. ${ }^{133,134}$ Mortality from any cause was higher with formula feeding than with breastfeeding in infants of HIV-1-positive mothers in rural Uganda. ${ }^{135}$ The timing of weaning is important, as the risk of transmission increases with the duration of exposure. Interestingly, exclusive breast milk feeding is less risky than mixed breast milk and solid food feeding. This might be because of inflammatory effects of solid food-associated pathogens at the weaning transition, continuity breaches, or increased intestinal epithelium permeability; however, studies to substantiate such mechanism through the measurement of inflammation marker calprotectin in feces have yielded the unexpected finding of higher levels of calprotectin in, exclusively, breast-fed infants. ${ }^{136}$ It is not clear where the portal of entry is: susceptible cells exist in tonsillar tissue but the saliva bathing the oral cavity also contains multiple anti HIV-1 factors including defensins, lysozyme, thrombospondin, and SLPI (reviewed in ref. ${ }^{137}$ ). Mucosal damage could facilitate entry of HIV-1 into sites where inflammation increases the influx of susceptible target cells and the secretion of inflammatory factors that increase expression of HIV-1 receptors and facilitate viral replication. With an intact mucosal surface, other mechanisms include transcytosis through epithelial cells, M cells in Peyer's patches or enterocytes-expressing galactosyl ceramide or Fc receptors, and DCs. ${ }^{138,139}$

It is generally agreed that $\operatorname{IgA}$ antibodies are not transported across the placenta and maternal milk provides IgA cover in the first months of an infant's life. However, in the case of HIV, specific IgAs present in the milk of infected mothers are not associated with protection. ${ }^{140}$ Although in vitro studies have shown that secretory IgA or IgM may inhibit transcytosis of HIV-1 across entrocytes. ${ }^{15,141}$ Infants may generate IgA responses under specific circumstances as shown in the replicationdefective recombinant canarypox virus HIV-1 pediatric vaccination trial. ${ }^{142,143}$ In a recent study conducted in Kenya, 8\% uninfected infants exposed to milk from HIV-1-infected mothers have been shown to have HIV-1 gp160-specific IgA antibodies in salivary secretions ${ }^{144}$ at a median time of one month after birth (13\% of infants that instead became infected had also HIV-1-specific IgAs). All the exposed uninfected infants with IgAs remained uninfected over 12 months of follow-up, suggesting a possible protective mechanism (although not necessarily IgA mediated) despite exposure sufficient to induce a humoral 
response. Unexposed uninfected controls had no IgA response. The finding parallels that of HIV-1-specific IgA1-neutralizing activity in IgG seronegative exposed uninfected men who engage in oral sex with men ${ }^{145}$ as well as older reports of IgA-neutralizing antibodies in plasma and mucosal compartments of highly exposed persistently seronegative sex workers and members of discordant couples. ${ }^{138,139,146-148}$

$\mathrm{CD} 8{ }^{+} \mathrm{T}$-cell responses have been detected in infants exposed to HIV-1-infected maternal milk, including some who did not become infected. ${ }^{149,150}$ Initial findings were, recently, confirmed in a large prospective cohort study, ${ }^{151}$ showing IFN- $\gamma$ responses to HIV-1 peptides in $47 \%$ of exposed uninfected infants during the first year of life. It is not clear whether such responses are protective or merely an indicator of exposure to defective virus or virus that is restricted in replication to mucosal or peripheral lymphoid tissues, as suggested by primate models. ${ }^{152}$

HIV-1 RNA viral load of breast milk, particularly cellassociated virus, ${ }^{153}$ is a determinant of transmission ${ }^{154}$ and HIV-1 and cytomegalovirus and Epstein-Barr virus shedding in milk from co-infected mothers are correlated $;{ }^{155}$ conversely, mastitis is not a good predictor of HIV-1 RNA viral load in milk. ${ }^{156} \alpha$-Defensins levels in breast milk from HIV-1-infected women correlated with viral load or subclinical mastitis, but the correlation with HIV-1 transmission to the baby was not confirmed in various studies. ${ }^{157,158}$ Breast milk levels of chemo-kines macrophage inflammatory protein- $1 \beta$ and regulated upon activation, normal T-cell expressed, and secreted were found to be higher in HIV-1-infected than uninfected mothers, and among HIV-1-infected women the transmitters had higher breast milk RANTES levels than non-transmitters. ${ }^{159}$ Intriguingly, low levels of IL-7-a stromal/epithelial cell-derived factor with anti-apoptotic and growth activity for peripheral T lymphocytes-in the milk of HIV-1-infected mothers have been associated with decreased transmission to babies, ${ }^{160}$ suggesting a possible role of milk CD4 ${ }^{+} \mathrm{T}$ cells in infant infection.

An understanding of the mucosal innate and adaptive immunological events associated with HIV-1 transmission in breast-feeding and the immunogenicity correlates of pediatric exposure to antigens through the oral route will be required to develop interventions including a mucosal vaccine. Currently, some of the authors and others are involved in perinatal HIV-1 vaccine trials (http://www.hptn.org/research_studies/ HPTN027StudyDocuments.asp\#Protocol), but we still lack a candidate that can induce mucosal immune responses.

\section{MALE CIRCUMCISION}

Apart from mechanical barriers such as condoms, the most effective way to prevent HIV-1 transmission through sexual intercourse is currently male circumcision, which can reduce female to male transmission by $60 \%{ }^{161-163}$ Details of the mechanism of protection are still being explored and are likely to pivot on the reduction in the infection targets in the male partner. Circumcision might simply be reducing the chances that any one exposure to the virus will result in infection. Although the surface area of the prepuce is small, under a thin layer of keratin the human foreskin mucosa contains $\mathrm{CD} 4^{+} \mathrm{T}$ cells, macrophages, and Langerhans cells (a subset of DCs) expressing the CCR5 HIV-1 co-receptor and is more susceptible to infection than the external foreskin. ${ }^{164-166}$ In an in vitro model of male mucosal infection, explanted foreskin, glans and urethral mucosa obtained from circumcision and gender reassignment surgery could be used to show HIV-1 protective effects of microbicides. ${ }^{167}$ As discussed above, the number of macrophages, DCs, and Langerhans cells increases with other genital infections, ${ }^{165}$ a possible basis for synergistic effects. Langerhans cells do not express the DC-SIGN receptor that mediates binding of HIV-1 to other DCs and their product langerin has been shown to inhibit HIV-1; ${ }^{168}$ however, they have membrane processes that sample the extra-mucosal milieu ${ }^{169,170}$ (although in vivo uptake of HIV-1 virions has not been formally shown) and could mediate trans-infection. In vitro studies of $\mathrm{CD} 34^{+}$hemopoietic progenitor derived, activated, langerin ${ }^{+}$, Birbeck granule $^{+}$ Langerhans cells ${ }^{171}$ show clustering of infectious HIV-1 virions within an intracellular multi-vesicular compartment with tetraspanin markers, $\mathrm{CD} 1 \mathrm{a}$ and langerin, suggesting that transcytosis might also occur in vivo.

Although randomized clinical trials support male circumcision's effectiveness in preventing heterosexual transmission, a recent meta-analysis of studies of male circumcision and homosexual transmission of HIV-1 did not find evidence for a protective effect of circumcision, even when the analysis was restricted to HIV-1-negative men engaging primarily in insertive anal sex. ${ }^{172}$ To our knowledge, the infectivity of HIV-1 present in rectal vs. vaginal mucosal secretions has not been compared, an association between circumcision and protection from homosexual transmission was, however, found for studies conducted before highly active anti retroviral therapy availability, suggesting that the protective effect of circumcision seen in heterosexual transmission might be overcome by higher sexual risk behavior in men who have sex with men. ${ }^{172}$ Circumcision was also shown to be associated with lower HIV-1 prevalence in a recent study of heterosexual transmission in African American men with known exposure to HIV-1, but the association was not significant for men whose exposure was not known. ${ }^{173}$

The acceptability of male circumcision varies with cultures and individuals, stimulating the search for non-surgical alternatives. It has been observed that estrogens cause an increase in keratinization and thickening of human vaginal epithelium and intravaginal estriol can increase resistance to SIV infection in ovariectomized rhesus macaques. ${ }^{174} \mathrm{~A}$ similar increase in keratinization occurs when estriol is applied to the foreskin and could be an alternative or complementary to circumcision. ${ }^{175}$ Understanding the mechanism of protection through circumcision could lead to new interventions.

\section{INNATE IMMUNITY INTHE GENITAL TRACT AND MICROBICIDES}

HIV-1 can travel by diffusion in interstitial spaces between stratified squamous epithelium cells lining the female genital tract ${ }^{176}$ and contact immature DCs, leading to uptake, DC maturation, 
and dissemination of the virions to draining lymph nodes and infection of susceptible CD4 ${ }^{+} \mathrm{CCR} 5^{+} \mathrm{T}$ cells. However, the heterosexual transmission rate of HIV-1 is lower than expected on the basis of viral loads in genital secretions and multiple mucosal innate protective mechanisms are probably involved. In the female genital tract, cervical vestibular glands secrete mucus that covers the cervical and vaginal epithelia and incorporates anti-microbial peptides. Neutrophils, submucosal serous cells, vaginal epithelial cells, and cervical glands contribute antiHIV- 1 factors lactoferrin and lysozyme, SLPI, $\alpha$ - and $\beta$ defensins. Combinations of these factors at physiological concentration can inhibit HIV-1 entry in vitro, ${ }^{113}$ whereas individual factors may need to be used at pharmacological concentrations to achieve the same effect. Human defensin genes exhibit copy number polymorphism and single nucleotide polymorphisms in the $\beta$-defensin-1 gene, which are associated with resistance to infections; homozygosity for the A69G polymorphism being overrepresented in HIV-1-exposed seronegative individuals compared with seropositives. ${ }^{177}$ Because of a stop mutation in the signal peptide sequence, humans do not produce $\theta$-defensin peptides, unlike other primates. However, synthetic $\theta$-defensin is remarkably active in vitro, protecting $\mathrm{T}$ cells from infection by clinical isolates of HIV-1. ${ }^{178}$

The menstrual cycle-related fluctuations in estradiol and progesterone hormones affect the thickness of the vaginal epithelium, $\mathrm{pH}$ of vaginal secretions, amount of mucus and levels of defensins, and SLPI in the endometrium, so that the protection afforded by these mechanisms is not constant. Innate non-specific protection can also be compromised by common conditions such as $\mathrm{BV}$ as mentioned earlier.

The use of microbicides represents a logical step to enhance the mucosal protection afforded by innate defenses. Early microbicide concepts involved potentiating the adsorbing capacity of mucus, $\mathrm{pH}$ control, or disruption of virions by detergents-an extension of non-specific natural protective mechanisms. The first surfactant-based microbicide-Nonoxynol-9-inactivates HIV-1 in vitro by disrupting the envelope lipid layer. It is also effective as a spermicide, used on condoms. However, it took the failure of efficacy trials to realize that regular Nonoxynol-9 use damages the vaginal epithelial layer, causing inflammation and paradoxically increasing the susceptibility to HIV $-1 .{ }^{5}$ In the same microbicide category Savvy (C31G cetyl betaine and myristamine oxide) had inconclusive phase 3 trials because of lower than expected HIV-1 infection incidence, ${ }^{179}$ and sodium lauryl sulphate is scheduled for phase 3 trials. "Vaginal protectors" microbicides currently in clinical trials in Africa (Buffergel (http://www.microbicide.org/galleries/clinical-trials/Microbici deOngoingClinicalTrials.3Nov08.pdf), Amphora (http://www. microbicide.org/galleries/clinical-trials/MicrobicidePlannedFu ndedClinicalTrials.3Nov08.pdf)) work by acidifying the vaginal milieu, maintaining mucosal conditions that are unfavorable to HIV. As they counteract the $\mathrm{pH}$-raising effect of semen, these are also spermicidal agents. Another approach involves lactobacilli of exogenous origin to supplement the natural vaginal flora. Lactobacilli are also being promoted as vectors of bioengineered proteins that act as HIV-1 entry inhibitors (CD4, gp41, cyanovirin). ${ }^{180-182}$ Cyanovirin-N is a fusion inhibiting lectin that binds high mannose residues in gp120 and has been effective in vitro on organ cultures and in macaque models with SHIV-1 challenges. ${ }^{183,184}$

Anionic polymer microbicides interfere with virus entry by having a negative electric charge complementary to the viral envelope protein. Carrageenan-based Carraguard was safe and well tolerated but ineffective; ${ }^{185}$ naphthalene sulfonate-based PRO2000 is still being evaluated, although one arm of the study was stopped early for futility. Recently, an interim report on the continuing arm revealed a $30 \%$ protective effect, just below statistical significance. ${ }^{186}$ Cellulose sulphate (Ushercell, Polydex Pharmaceuticals Limited, Toronto, Canada) binds to gp120 and is inhibitory in vitro. However, phase 3 trials were stopped when an interim analysis showed higher incidence in HIV-1 infections in the cellulose sulphate group. It has, recently, been appreciated that cellulose sulphate (and other polyanions such as dextrin sulphate and PRO2000) have a biphasic effect, inhibiting HIV-1 infection at high concentration and enhancing it at low concentration. ${ }^{187}$ Synthetic PSC-RANTES ${ }^{188}$ and CMPD $167^{189}$ bind to the CCR5 co-receptor and prevent virus attachment. Protective effect was shown in macaque models with SHIV-1 challenge and combination with synthetic peptides that bind to gp120 and gp41 can provide additional protection. ${ }^{190}$ These microbicides do not affect the minority of HIV-1 strains that use the CXCR4 co-receptor-this loophole might have to be addressed if successful usage of CCR 5 blockers resulted in selection of CXCR4 strains, for instance, by inclusion of fusion inhibitory peptide T-1249. ${ }^{191}$

A new generation of microbicide gels capitalizes on the effectiveness of antiretroviral compounds with specific anti-HIV-1 activity by incorporating reverse transcriptase inhibitors such as tenofovir in a form of pre-exposure prophylaxis. Low levels of systemic absorption occur and resistance mutations have not been observed except in those individuals already on anti retroviral therapy at enrollment. A phase $2 \mathrm{~B}$ trial of $1 \%$ tenofovir gel is ongoing-having just completed enrollment-in South Africa. (http://www.microbicide.org/galleries/clinicaltrials/MicrobicideOngoingClinicalTrials.3Nov08.pdf). Other microbicides under evaluation incorporate non-nucleoside reverse transcriptase inhibitors TMC120 (Dapivirine, Tibotec Pharmaceuticals Limited, Mechelen, Belgium) and UC781. ${ }^{192}$ This generation of microbicides including antiretrovirals has the potential to keep working even if the first mucosal barrier-the epithelial layer-is breached and the virus infects $\mathrm{CD} 4{ }^{+} \mathrm{T}$ cells, macrophages, or DCs present in the vaginal or rectal submucosa. This could actually have a beneficial effect, slowing viral replication, preventing depletion of $\mathrm{CD} 4^{+} \mathrm{T}$ cells in the intestinal lamina propria and allowing acquired immune responses to develop, effectively turning an abortive infection into an immunization. Protection and priming of SIV-specific T-cell responses was indeed observed in a rectal transmission model of macaques treated with tenofovir gel. ${ }^{193}$

In summary, the microbicide field is using the known viral entry and immune mechanisms to find alternative approaches to prevention; at this stage in is not known how other factors 
such as STIs, helminths, compliance, and the diversity of HIV-1 subtypes in Africa will affect their efficacy.

\section{CONCLUSION}

The control of the HIV-1 epidemic will need a multi-pronged approach and additional tools are urgently needed. Better understanding of the immunology of the mucosal surface provides an important opportunity for such discoveries. This research cannot be confined to developed nations, given the unique characteristics of the epidemic in Africa. We have reviewed some of the current literature on the mucosal immunology of co-infections commonly occurring in Africa, immunological aspects of current interventions, and discussed some challenges of developing a mucosal vaccine against HIV-1. A number of gaps in our knowledge of HIV-1 transmission need to be addressed and some have already been identified in the Global HIV-1 Vaccine Enterprise Strategic plan. Some of the issues discussed in this review are also a priority in our research programs as we continue to build capacity in HIV-1 vaccine research and trials in Africa.

\section{ACKNOWLEDGMENTS}

P.P. and P.K. are supported by the Medical Research Council of the UK through the MRC/UVRI Uganda Research Unit on AIDS; additional support is coming from the Center for HIV-1 and AIDS Immunology (CHAVI). P.K. also has support from the International AIDS Vaccine Initiative through the UVRI/IAVI HIV-1 vaccine Program. J.G. is supported by the International AIDS Vaccine Initiative, including funding from USAID Cooperative Agreement Number: GPO-A-00-06-00005-00. (The contents of this paper do not necessarily reflect the views of USAID or the US government.) V.R.G.R. is supported by Imperial College London and by the International AIDS Vaccine Initiative.

\section{DISCLOSURE}

The authors declare no conflict of interest.

(c) 2009 Society for Mucosal Immunology

\section{REFERENCES}

1. Gouws, E., White, P.J., Stover, J. \& Brown, T. Short term estimates of adult HIV incidence by mode of transmission: Kenya and Thailand as examples. Sex. Transm. Infect. 82 (Suppl 3), iii51-iii55 (2006).

2. Caceres, C.F., Konda, K., Segura, E.R. \& Lyerla, R. Epidemiology of male same-sex behaviour and associated sexual health indicators in low- and middle-income countries: 2003-2007 estimates. Sex. Transm. Infect. 84 (Suppl 1), i49-i56 (2008).

3. Caceres, C., Konda, K., Pecheny, M., Chatterjee, A. \& Lyerla, R. Estimating the number of men who have sex with men in low and middle income countries. Sex. Transm. Infect. 82 (Suppl 3), iii3-iii9 (2006).

4. Watson-Jones, D. et al. Effect of herpes simplex suppression on incidence of HIV among women in Tanzania. N. Engl. J. Med. 358, 1560-1571 (2008)

5. Roddy, R.E. et al. A controlled trial of nonoxynol 9 film to reduce male-to-female transmission of sexually transmitted diseases. N. Engl. J. Med. 339, 504-510 (1998).

6. Buchbinder, S.P. et al. Efficacy assessment of a cell-mediated immunity HIV-1 vaccine (the Step Study): a double-blind, randomised, placebo-controlled, test-of-concept trial. Lancet 372, 1881-1893 (2008).

7. Haaland, R.E. et al. Inflammatory genital infections mitigate a severe genetic bottleneck in heterosexual transmission of subtype A and C HIV1. PLoS Pathog. 5, e1000274 (2009).

8. Hladik, F. \& McElrath, M.J. Setting the stage: host invasion by HIV. Nat. Rev. Immunol. 8, 447-457 (2008).

9. Brenchley, J.M. \& Douek, D.C. HIV infection and the gastrointestinal immune system. Mucosal Immunol. 1, 23-30 (2008).
10. Hu, J., Gardner, M.B. \& Miller, C.J. Simian immunodeficiency virus rapidly penetrates the cervicovaginal mucosa after intravaginal inoculation and infects intraepithelial dendritic cells. J. Virol. 74, 6087-6095 (2000).

11. Spira, A.I. et al. Cellular targets of infection and route of viral dissemination after an intravaginal inoculation of simian immunodeficiency virus into rhesus macaques. J. Exp. Med. 183, 215-225 (1996).

12. Zhang, Z. et al. Sexual transmission and propagation of SIV and HIV in resting and activated CD4+ T cells. Science 286, 1353-1357 (1999).

13. Wu, Z., Chen, Z. \& Phillips, D.M. Human genital epithelial cells capture cell-free human immunodeficiency virus type 1 and transmit the virus to CD4+ Cells: implications for mechanisms of sexual transmission. J. Infect. Dis. 188, 1473-1482 (2003).

14. Berlier, W. et al. Selective sequestration of $X 4$ isolates by human genital epithelial cells: implication for virus tropism selection process during sexual transmission of HIV. J. Med. Virol. 77, 465-474 (2005).

15. Bomsel, M. Transcytosis of infectious human immunodeficiency virus across a tight human epithelial cell line barrier. Nat. Med. 3, 42-47 (1997).

16. Hladik, F. et al. Initial events in establishing vaginal entry and infection by human immunodeficiency virus type-1. Immunity. 26, 257-270 (2007).

17. Mattapallil, J.J. et al. Massive infection and loss of memory CD4+ T cells in multiple tissues during acute SIV infection. Nature 434, 1093-1097 (2005).

18. Li, Q. et al. Peak SIV replication in resting memory CD4+ T cells depletes gut lamina propria CD4+ T cells. Nature 434, 1148-1152 (2005).

19. Li, Q. et al. Simian immunodeficiency virus-induced intestinal cell apoptosis is the underlying mechanism of the regenerative enteropathy of early infection. J. Infect. Dis. 197, 420-429 (2008).

20. Derdeyn, C.A. \& Silvestri, G. Viral and host factors in the pathogenesis of HIV infection. Curr. Opin. Immunol. 17, 366-373 (2005).

21. Keele, B.F. et al. Identification and characterization of transmitted and early founder virus envelopes in primary HIV-1 infection. Proc. Natl. Acad. Sci. USA 105, 7552-7557 (2008).

22. Salazar-Gonzalez, J.F. et al. Deciphering human immunodeficiency virus type 1 transmission and early envelope diversification by single-genome amplification and sequencing. J. Virol. 82, 3952-3970 (2008).

23. Barouch, D.H. Challenges in the development of an HIV-1 vaccine. Nature 455, 613-619 (2008).

24. Walker, B.D. \& Burton, D.R. Toward an AIDS vaccine. Science $\mathbf{3 2 0}$ 760-764 (2008).

25. Valentine, L.E. et al. Recognition of escape variants in ELISPOT does not always predict CD8+ T-cell recognition of simian immunodeficiency virus-infected cells expressing the same variant sequences. J. Virol. 82, 575-581 (2008).

26. Burton, D.R. et al. HIV vaccine design and the neutralizing antibody problem. Nat. Immunol. 5, 233-236 (2004).

27. Steinbrook, R. One step forward, two steps back--will there ever be an AIDS vaccine? N. Engl. J. Med. 357, 2653-2655 (2007).

28. McElrath, M.J. et al. HIV-1 vaccine-induced immunity in the test-of-concept Step Study: a case-cohort analysis. Lancet 372, 1894-1905 (2008).

29. Koff, W.C. et al. Replicating viral vectors as HIV vaccines Summary Report from IAVI Sponsored Satellite Symposium, International AIDS Society Conference, July 22, 2007. Biologicals 36, 277-286 (2008).

30. Shattock, R.J., Haynes, B.F., Pulendran, B., Flores, J. \& Esparza, J. Improving defences at the portal of HIV entry: mucosal and innate immunity. PLoS Med. 5, e81 (2008).

31. Polonis, V.R. et al. Recent advances in the characterization of HIV-1 neutralization assays for standardized evaluation of the antibody response to infection and vaccination. Virology 375, 315-320 (2008).

32. Chomont, N. et al. Neutralizing monoclonal antibodies to human immunodeficiency virus type 1 do not inhibit viral transcytosis through mucosal epithelial cells. Virology 370, 246-254 (2008).

33. Simek, M. et al. Rapid and efficient identification of individuals with broad neutralizing activity from diverse HIV-1 epidemics using a multi-clade pseudo-virus screening panel and analytical selection algorithm. In AIDS Vaccine 2008. AIDS Res. Hum. Retroviruses 24(S1), 1-175 (2008).

34. Macpherson, A.J., McCoy, K.D., Johansen, F.E. \& Brandtzaeg, P. The immune geography of IgA induction and function. Mucosal Immunol. 1, 11-22 (2008).

35. Stanley, M. Immunobiology of HPV and HPV vaccines. Gynecol. Oncol. 109, S15-S21 (2008). 
36. Nardelli-Haefliger, D. et al. Specific antibody levels at the cervix during the menstrual cycle of women vaccinated with human papillomavirus 16 virus-like particles. J. Natl. Cancer Inst. 95, 1128-1137 (2003).

37. Wu, X., Hall, S. \& Jackson, S. Tropism-restricted neutralization by secretory IgA from parotid saliva of HIV type 1-infected individuals. AIDS Res. Hum. Retroviruses 19, 275-281 (2003).

38. Alexander, R. \& Mestecky, J. Neutralizing antibodies in mucosal secretions: IgG or IgA? Curr. HIV Res. 5, 588-593 (2007).

39. Parker, C.E. et al. Fine definition of the epitope on the gp41 glycoprotein of human immunodeficiency virus type 1 for the neutralizing monoclonal antibody 2F5. J. Virol. 75, 10906-10911 (2001).

40. Nardelli-Haefliger, D. et al. Immune responses induced by lower airway mucosal immunisation with a human papillomavirus type 16 virus-like particle vaccine. Vaccine 23, 3634-3641 (2005).

41. Eslahpazir, J. et al. Infection of macrophages and dendritic cells with primary R5-tropic human immunodeficiency virus type 1 inhibited by natural polyreactive anti-CCR5 antibodies purified from cervicovaginal secretions. Clin. Vaccine Immunol. 15, 872-884 (2008).

42. McMichael, A.J. \& Hanke, T. HIV vaccines 1983-2003. Nat. Med. 9 874-880 (2003).

43. Santra, S. et al. A centralized gene-based HIV-1 vaccine elicits broad cross-clade cellular immune responses in rhesus monkeys. Proc. Natl. Acad. Sci. USA 105, 10489-10494 (2008).

44. Letourneau, S. et al. Design and pre-clinical evaluation of a universal HIV-1 vaccine. PLoS ONE 2, e984 (2007).

45. Peters, B.S. et al. Studies of a prophylactic HIV-1 vaccine candidate based on modified vaccinia virus Ankara (MVA) with and without DNA priming: effects of dosage and route on safety and immunogenicity. Vaccine 25, 2120-2127 (2007).

46. Kozlowski, P.A. \& Neutra, M.R. The role of mucosal immunity in prevention of HIV transmission. Curr. Mol. Med. 3, 217-228 (2003).

47. Neutra, M.R. \& Kozlowski, P.A. Mucosal vaccines: the promise and the challenge. Nat. Rev. Immunol. 6, 148-158 (2006).

48. Girard, M.P. et al. Mucosal immunity and HIV/AIDS vaccines. Report of an International Workshop, 28-30 October 2007. Vaccine 26, 3969-3977 (2008)

49. Yuki, Y., Nochi, T. \& Kiyono, H. Progress towards an AIDS mucosal vaccine: an overview. Tuberculosis (Edinb) 87(Suppl 1), S35-S44 (2007)

50. Belyakov, I.M. et al. Impact of vaccine-induced mucosal high-avidity CD8+ CTLs in delay of AIDS viral dissemination from mucosa. Blood 107, 3258-3264 (2006).

51. Kent, S.J. et al. Mucosally-administered human-simian immunodeficiency virus DNA and fowlpoxvirus-based recombinant vaccines reduce acute phase viral replication in macaques following vaginal challenge with CCR5-tropic SHIVSF162P3. Vaccine 23, 5009-5021 (2005)

52. Li, Z. et al. Novel vaccination protocol with two live mucosal vectors elicits strong cell-mediated immunity in the vagina and protects against vaginal virus challenge. J. Immunol. 180, 2504-2513 (2008).

53. Genesca, M., McChesney, M.B. \& Miller, C.J. Antiviral CD8+ T cells in the genital tract control viral replication and delay progression to AIDS after vaginal SIV challenge in rhesus macaques immunized with virulence attenuated SHIV 89.6. J. Intern. Med. 265, 67-77 (2009).

54. Kozlowski, P.A., Cu-Uvin, S., Neutra, M.R. \& Flanigan, T.P. Comparison of the oral, rectal, and vaginal immunization routes for induction of antibodies in rectal and genital tract secretions of women. Infect. Immun. 65, 1387-1394 (1997).

55. Kozlowski, P.A., Cu-Uvin, S., Neutra, M.R. \& Flanigan, T.P. Mucosal vaccination strategies for women. J. Infect. Dis. 179 (Suppl 3), S493-S498 (1999).

56. Kozlowski, P.A. et al. Differential induction of mucosal and systemic antibody responses in women after nasal, rectal, or vaginal immunization: influence of the menstrual cycle. J. Immunol. 169, 566-574 (2002).

57. Stanberry, L.R. et al. Glycoprotein-D-adjuvant vaccine to prevent genita herpes. N. Engl. J. Med. 347, 1652-1661 (2002)

58. Staats, H.F., Montgomery, S.P. \& Palker, T.J. Intranasal immunization is superior to vaginal, gastric, or rectal immunization for the induction of systemic and mucosal anti-HIV antibody responses. AIDS Res. Hum. Retroviruses 13, 945-952 (1997).

59. Mantis, N.J., Kozlowski, P.A., Mielcarz, D.W., Weissenhorn, W. \& Neutra M.R. Immunization of mice with recombinant gp41 in a systemic prime/ mucosal boost protocol induces HIV-1-specific serum lgG and secretory IgA antibodies. Vaccine 19, 3990-4001 (2001).
60. Chen, H. Recent advances in mucosal vaccine development. J. Control Release 67, 117-128 (2000).

61. Gaucher, D. et al. Yellow fever vaccine induces integrated multilineage and polyfunctional immune responses. J. Exp. Med. 205, 3119-3131 (2008)

62. Kato, M. et al. Induction of Gag-specific T-cell responses by therapeutic immunization with a Gag-expressing Sendai virus vector in macaques chronically infected with simian-human immunodeficiency virus. Vaccine 23, 3166-3173 (2005).

63. Takeda, A. et al. Evaluation of the immunogenicity of replicationcompetent V-knocked-out and replication-defective F-deleted Sendai virus vector-based vaccines in macaques. Vaccine 26 , 6839-6843 (2008).

64. Boaz, M.J. et al. Measuring T-cell immunity in HIV vaccine clinical trials: PBMC and ELISPOT assay proficiency concordance in laboratories from 3 continents. Clin. Vaccine Immunol. 16, 147-155 (2008).

65. Gilmour, J., Stevens, W., Gray, C. \& de Souza, M. Laboratory expansion to large-scale international HIV preventive vaccine trials. Curr. Opin. HIV AIDS 2, 201-206 (2007).

66. Gumbi, P.P. et al. Impact of mucosal inflammation on cervical human immunodeficiency virus (HIV-1)-specific CD8 T-cell responses in the female genital tract during chronic HIV infection. J. Virol. 82, 8529-8536 (2008).

67. Kozlowski, P.A. et al. Modified wick method using Weck-Cel sponges for collection of human rectal secretions and analysis of mucosal HIV antibody. J. Acquir. Immune. Defic. Syndr. 24, 297-309 (2000).

68. Ferre, A.L. et al. Mucosal immune responses to HIV-1 in elite controllers: a potential correlate of immune control. Blood (2008). (E-pub ahead of print).

69. Critchfield, J.W. et al. Magnitude and complexity of rectal mucosa HIV-1-specific CD8+ T-cell responses during chronic infection reflect clinical status. PLoS ONE 3, e3577 (2008).

70. Anton, P.A. et al. Differential immunogenicity of vaccinia and HIV-1 components of a human recombinant vaccine in mucosal and blood compartments. Vaccine 26, 4617-4623 (2008).

71. Fleming, D.T. \& Wasserheit, J.N. From epidemiological synergy to public health policy and practice: the contribution of other sexually transmitted diseases to sexual transmission of HIV infection. Sex Transm. Infect. 75, 3-17 (1999).

72. Kaleebu, P., Elliott, A.M. \& Whittle, H.C. The immune response to infection. In Principles of Medicine in Africa (Parry, E., Godfrey, R. Mabey, D. \& Gill, G., eds) 114-140 (Cambridge University Press, Cambridge, 2004).

73. Galvin, S.R. \& Cohen, M.S. The role of sexually transmitted diseases in HIV transmission. Nat. Rev. Microbiol. 2, 33-42 (2004).

74. Sagar, M. et al. Identification of modifiable factors that affect the genetic diversity of the transmitted HIV-1 population. AIDS 18, 615-619 (2004).

75. Kaul, R. et al. The genital tract immune milieu: an important determinant of HIV susceptibility and secondary transmission. J. Reprod. Immunol. 77, 32-40 (2008).

76. Zhao, X. et al. Vaginal submucosal dendritic cells, but not Langerhans cells, induce protective Th1 responses to herpes simplex virus-2. J. Exp. Med. 197, 153-162 (2003).

77. lijima, N., Thompson, J.M. \& Iwasaki, A. Dendritic cells and macrophages in the genitourinary tract. Mucosal Immunol. 1, 451-459 (2008).

78. Abel, K. et al. Simian-human immunodeficiency virus SHIV89.6-induced protection against intravaginal challenge with pathogenic SIVmac239 is independent of the route of immunization and is associated with a combination of cytotoxic T-lymphocyte and alpha interferon responses. J. Virol. 77, 3099-3118 (2003).

79. Clay, C.C., Rodrigues, D.S., Harvey, D.J., Leutenegger, C.M. \& Esser, U. Distinct chemokine triggers and in vivo migratory paths of fluorescein dye-labeled T Lymphocytes in acutely simian immunodeficiency virus SIVmac251-infected and uninfected macaques. J. Virol. 79, 13759-13768 (2005)

80. Wu, L. Biology of HIV mucosal transmission. Curr. Opin. HIV AIDS 3, 534-540 (2008).

81. Weiss, $\mathrm{H}$. Epidemiology of herpes simplex virus type 2 infection in the developing world. Herpes 11 (Suppl 1), 24A-35A (2004).

82. Abu-Raddad, L.J. et al. Genital herpes has played a more important role than any other sexually transmitted infection in driving HIV prevalence in Africa. PLoS ONE 3, e2230 (2008). 
83. Schacker, T., Zeh, J., Hu, H.L., Hill, E. \& Corey, L. Frequency of symptomatic and asymptomatic herpes simplex virus type 2 reactivations among human immunodeficiency virus-infected men. J. Infect. Dis. 178, 1616-1622 (1998).

84. Schacker, T. et al. Frequent recovery of HIV-1 from genital herpes simplex virus lesions in HIV-1-infected men. JAMA 280, 61-66 (1998)

85. Mosca, J.D. et al. Activation of human immunodeficiency virus by herpesvirus infection: identification of a region within the long terminal repeat that responds to a trans-acting factor encoded by herpes simplex virus 1. Proc. Natl. Acad. Sci. USA 84, 7408-7412 (1987).

86. Golden, M.P. et al. Activation of human immunodeficiency virus by herpes simplex virus. J. Infect. Dis. 166, 494-499 (1992).

87. Sobngwi-Tambekou, J. et al. Effect of HSV-2 serostatus on acquisition of HIV by young men: results of a longitudinal study in Orange Farm, South Africa. J. Infect. Dis. 199, 958-964 (2009).

88. Rando, R.F., Pellett, P.E., Luciw, P.A., Bohan, C.A. \& Srinivasan, A. Transactivation of human immunodeficiency virus by herpesviruses. Oncogene 1, 13-18 (1987)

89. Kamali, A. et al. A community randomized controlled trial to investigate impact of improved STD management and behavioural interventions on HIV incidence in rural Masaka, Uganda: trial design, methods and baseline findings. Trop. Med. Int. Health 7, 1053-1063 (2002).

90. Gray, R.H. et al. Randomized trial of presumptive sexually transmitted disease therapy during pregnancy in Rakai, Uganda. Am. J. Obstet. Gynecol. 185, 1209-1217 (2001).

91. Wawer, M.J. et al. Control of sexually transmitted diseases for AIDS prevention in Uganda: a randomised community trial. Rakai Project Study Group. Lancet 353, 525-535 (1999).

92. Gray, R.H. et al. Relative risks and population attributable fraction of incident HIV associated with symptoms of sexually transmitted diseases and treatable symptomatic sexually transmitted diseases in Rakai District, Uganda. Rakai Project Team. AIDS 13, 2113-2123 (1999).

93. Zuckerman, R.A. et al. Herpes simplex virus (HSV) suppression with valacyclovir reduces rectal and blood plasma HIV-1 levels in HIV-1/HSV2-seropositive men: a randomized, double-blind, placebo-controlled crossover trial. J. Infect. Dis. 196, 1500-1508 (2007).

94. Zuckerman, R.A. et al. HSV suppression reduces seminal HIV-1 levels in HIV-1/HSV-2 co-infected men who have sex with men. AIDS 23, 479-483. (2009).

95. Delany, S. et al. Impact of aciclovir on genital and plasma HIV-1 RNA in HSV-2/HIV-1 co-infected women: a randomized placebo-controlled trial in South Africa. AIDS 23, 461-469 (2009).

96. Celum, C. et al. Effect of aciclovir on HIV-1 acquisition in herpes simplex virus 2 seropositive women and men who have sex with men: a randomised, double-blind, placebo-controlled trial. Lancet 371, 2109-2119 (2008)

97. Cohen, M.S. HIV and sexually transmitted diseases: lethal synergy. Top HIV. Med. 12, 104-107 (2004).

98. Sheung, A. et al. Mucosal Neisseria gonorrhoeae coinfection during HIV acquisition is associated with enhanced systemic HIV-specific CD8 T-cel responses. AIDS 22, 1729-1737 (2008).

99. Anzala, A.O. et al. Acute sexually transmitted infections increase human immunodeficiency virus type 1 plasma viremia, increase plasma type 2 cytokines, and decrease CD4 cell counts. J. Infect. Dis. 182, 459-466 (2000).

100. Kaul, R. et al. Gonococcal cervicitis is associated with reduced systemic CD8+ T cell responses in human immunodeficiency virus type 1-infected and exposed, uninfected sex workers. J. Infect. Dis. 185, 1525-1529 (2002).

101. Boulton, I.C. \& Gray-Owen, S.D. Neisserial binding to CEACAM1 arrests the activation and proliferation of CD4+ T lymphocytes. Nat. Immunol. 3 229-236 (2002).

102. Yu, Q. et al. A dangerous liaison between two major STD pathogens, HIV and Neisseria gonorrhoeae: Opa52 protein of Neisseria gonorrhoeae impairs dendritic cell maturation and subsequent HIV-specific T cell immunity. In Keystone Conference on the Molecular Mechanisms of HIV Pathogenesis. (Whistler, BC, Canada, 2004).

103. Liu, X. et al. Gonococcal lipooligosaccharide suppresses HIV infection in human primary macrophages through induction of innate immunity. J. Infect. Dis. 194, 751-759 (2006).
104. Mesa, C., de Leon, J., Rigley, K. \& Fernandez, L.E. Very small size proteoliposomes derived from Neisseria meningitidis: an effective adjuvant for dendritic cell activation. Vaccine $\mathbf{2 4 ( S u p p l}$ 2), S2-S42-3 (2006)

105. Venier, C., Guthmann, M.D., Fernandez, L.E. \& Fainboim, L. Innate-immunity cytokines induced by very small size proteoliposomes, a Neisseria-derived immunological adjuvant. Clin. Exp. Immunol. 147, 379-388 (2007).

106. Atashili, J., Poole, C., Ndumbe, P.M., Adimora, A.A. \& Smith, J.S. Bacterial vaginosis and $\mathrm{HIV}$ acquisition: a meta-analysis of published studies. AIDS 22, 1493-1501 (2008).

107. Sewankambo, N. et al. HIV-1 infection associated with abnormal vaginal flora morphology and bacterial vaginosis. Lancet 350, 546-550 (1997).

108. Cole, A.M. \& Cole, A.L. Antimicrobial polypeptides are key anti-HIV-1 effector molecules of cervicovaginal host defense. Am. J. Reprod. Immunol. 59, 27-34 (2008).

109. Valore, E.V., Wiley, D.J. \& Ganz, T. Reversible deficiency of antimicrobial polypeptides in bacterial vaginosis. Infect. Immun. 74, 5693-5702 (2006).

110. Zasloff, M. Antimicrobial peptides of multicellular organisms. Nature 415, 389-395 (2002)

111. Shugars, D.C., Alexander, A.L., Fu, K. \& Freel, S.A. Endogenous salivary inhibitors of human immunodeficiency virus. Arch. Oral Biol. 44, 445-453 (1999).

112. Shugars, D.C. Endogenous mucosal antiviral factors of the oral cavity. J. Infect. Dis. 179(Suppl 3), S431-S435 (1999).

113. Venkataraman, N., Cole, A.L., Svoboda, P., Pohl, J. \& Cole, A.M. Cationic polypeptides are required for anti-HIV-1 activity of human vaginal fluid. J. Immunol. 175, 7560-7567 (2005).

114. Pillay, K. et al. Secretory leukocyte protease inhibitor in vaginal fluids and perinatal human immunodeficiency virus type 1 transmission. J. Infect. Dis. 183, 653-656 (2001).

115. McNeely, T.B. et al. Secretory leukocyte protease inhibitor: a human saliva protein exhibiting anti-human immunodeficiency virus 1 activity in vitro. J. Clin. Invest. 96, 456-464 (1995).

116. Ma, G. et al. Secretory leukocyte protease inhibitor binds to annexin II, a cofactor for macrophage HIV-1 infection. J. Exp. Med. 200, 1337-1346 (2004).

117. Sturm-Ramirez, K., Gaye-Diallo, A., Eisen, G., Mboup, S. \& Kanki, P.J. High levels of tumor necrosis factor-alpha and interleukin-1 beta in bacterial vaginosis may increase susceptibility to human immunodeficiency virus. J. Infect. Dis. 182, 467-473 (2000).

118. St John, E., Mares, D. \& Spear, G.T. Bacterial vaginosis and host immunity. Curr. HIVIAIDS Rep. 4, 22-28 (2007).

119. St John, E.P. et al. Effect of mucosal fluid from women with bacterial vaginosis on HIV trans-infection mediated by dendritic cells. Virology 385, 22-27 (2009).

120. Spear, G.T., St John, E. \& Zariffard, M.R. Bacterial vaginosis and human immunodeficiency virus infection. AIDS Res. Ther. 4, 25 (2007).

121. Brown, M., Mawa, P.A., Kaleebu, P. \& Elliott, A.M. Helminths and HIV infection: epidemiological observations on immunological hypotheses. Parasite Immunol. 28, 613-623 (2006).

122. Kjetland, E.F. et al. Association between genital schistosomiasis and HIV in rural Zimbabwean women. AIDS 20, 593-600 (2006).

123. Chenine, A.L. et al. Acute Schistosoma mansoni infection increases susceptibility to systemic SHIV clade C infection in rhesus macaques after mucosal virus exposure. PLoS Negl. Trop. Dis. 2, e265 (2008).

124. Actor, J.K. et al. Helminth infection results in decreased virus-specific CD8+ cytotoxic T-cell and Th1 cytokine responses as well as delayed virus clearance. Proc. Natl. Acad. Sci. USA 90, 948-952 (1993).

125. Sabin, E.A., Araujo, M.I., Carvalho, E.M. \& Pearce, E.J. Impairment of tetanus toxoid-specific Th1-like immune responses in humans infected with Schistosoma mansoni. J. Infect. Dis. 173, 269-272 (1996).

126. Cooper, P.J. et al. Human infection with Ascaris lumbricoides is associated with suppression of the interleukin-2 response to recombinant cholera toxin $B$ subunit following vaccination with the live oral cholera vaccine CVD 103-HgR. Infect. Immun. 69, 1574-1580 (2001).

127. Cooper, P.J. et al. Human onchocerciasis and tetanus vaccination: impact on the postvaccination antitetanus antibody response. Infect. Immun. 67, 5951-5957 (1999).

128. Su, Z., Segura, M., Morgan, K., Loredo-Osti, J.C. \& Stevenson, M.M. Impairment of protective immunity to blood-stage malaria by concurrent nematode infection. Infect. Immun. 73, 3531-3539 (2005). 
129. Kullberg, M.C., Pearce, E.J., Hieny, S.E., Sher, A. \& Berzofsky, J.A Infection with Schistosoma mansoni alters Th1/Th2 cytokine responses to a non-parasite antigen. J. Immunol. 148, 3264-3270 (1992).

130. Da'Dara, A.A. et al. Helminth infection suppresses T-cell immune response to HIV-DNA-based vaccine in mice. Vaccine $\mathbf{2 4 , 5 2 1 1 - 5 2 1 9}$ (2006).

131. Page-Shafer, K., Sweet, S., Kassaye, S. \& Ssali, C. (C2) Saliva, breast milk, and mucosal fluids in HIV transmission. Adv. Dent. Res. 19, 152-157 (2006).

132. Chasela, C. et al. Risk factors for late postnatal transmission of human immunodeficiency virus type 1 in sub-Saharan Africa. Pediatr. Infect. Dis. J. 27, 251-256 (2008)

133. WHO update on global guidance in the area of HIV and infant feeding. Food Nutr. Bull. 25, 97-98 (2004).

134. Doherty, T. et al. Effectiveness of the WHO/UNICEF guidelines on infant feeding for HIV-positive women: results from a prospective cohort study in South Africa. AIDS 21, 1791-1797 (2007).

135. Kagaayi, J. et al. Survival of infants born to HIV-positive mothers, by feeding modality, in Rakai, Uganda. PLoS ONE 3, e3877 (2008),

136. Dorosko, S.M., Mackenzie, T. \& Connor, R.I. Fecal calprotectin concentrations are higher in exclusively breastfed infants compared to those who are mixed-fed. Breastfeed Med. 3, 117-119 (2008).

137. Campo, J. et al. Oral transmission of HIV, reality or fiction? An update. Oral Dis. 12, 219-228 (2006).

138. Devito, C. et al. Mucosal and plasma lgA from HIV-1-exposed uninfected individuals inhibit HIV-1 transcytosis across human epithelial cells. J. Immunol. 165, 5170-5176 (2000).

139. Devito, C. et al. Mucosal and plasma IgA from HIV-exposed seronegative individuals neutralize a primary HIV-1 isolate. AIDS 14, 1917-1920 (2000).

140. Kuhn, L. et al. Hiv-specific secretory IgA in breast milk of HIV-positive mothers is not associated with protection against HIV transmission among breast-fed infants. J. Pediatr. 149, 611-616 (2006).

141. Bomsel, M. et al. Intracellular neutralization of HIV transcytosis across tight epithelial barriers by anti-HIV envelope protein dlgA or lgM. Immunity 9, 277-287 (1998).

142. Johnson, D.C. et al. Safety and immunogenicity of an HIV-1 recombinant canarypox vaccine in newborns and infants of HIV-1-infected women. J. Infect. Dis. 192, 2129-2133 (2005).

143. McFarland, E.J. et al. HIV-1 vaccine induced immune responses in newborns of HIV-1 infected mothers. AIDS 20, 1481-1489 (2006).

144. Farquhar, C. et al. Salivary human immunodeficiency virus (HIV)-1specific immunoglobulin A in HIV-1-exposed infants in Kenya. Clin. Exp. Immunol. 153, 37-43 (2008)

145. Hasselrot, K. et al. Oral HIV-exposure elicits mucosal HIV-neutralizing antibodies in uninfected men who have sex with men. AIDS 23, 329-333 (2009).

146. Broliden, K. et al. Functional HIV-1 specific IgA antibodies in HIV-1 exposed, persistently IgG seronegative female sex workers. Immunol. Lett. 79, 29-36 (2001).

147. Clerici, M. et al. Serum IgA of HIV-exposed uninfected individuals inhibit HIV through recognition of a region within the alpha-helix of gp41. AIDS $16,1731-1741$ (2002)

148. Devito, C. et al. Cross-clade HIV-1-specific neutralizing lgA in mucosal and systemic compartments of HIV-1-exposed, persistently seronegative subjects. J. Acquir. Immune. Defic. Syndr. 30, 413-420 (2002).

149. Rowland-Jones, S.L. et al. HIV-specific cytotoxic T-cell activity in an HIV-exposed but uninfected infant. Lancet 341, 860-861 (1993).

150. Legrand, F.A. et al. Strong HIV-1-specific T cell responses in HIV-1-exposed uninfected infants and neonates revealed after regulatory T cell removal. PLoS ONE 1, e102 (2006).

151. John-Stewart, G.C. et al. HIV-1-specific cytotoxic T lymphocytes and breast milk HIV-1 transmission. J. Infect. Dis. (2009). (E-pub ahead of print).

152. Miller, C.J. et al. Intravaginal inoculation of rhesus macaques with cell-free simian immunodeficiency virus results in persistent or transient viremia. J. Virol. 68, 6391-6400 (1994).

153. Koulinska, I.N. et al. Transmission of cell-free and cell-associated HIV-1 through breast-feeding. J. Acquir. Immune. Defic. Syndr. 41, 93-99 (2006).

154. Semrau, K. et al. Temporal and lateral dynamics of HIV shedding and elevated sodium in breast milk among HIV-positive mothers during the first 4 months of breast-feeding. J. Acquir. Immune. Defic. Syndr. 47 , 320-328 (2008)

155. Gantt, S. et al. Cytomegalovirus and Epstein-Barr virus in breast milk are associated with HIV-1 shedding but not with mastitis. AIDS 22 1453-1460 (2008).

156. Gantt, S. et al. Laboratory indicators of mastitis are not associated with elevated HIV-1 DNA loads or predictive of HIV-1 RNA loads in breast milk. J. Infect. Dis. 196, 570-576 (2007).

157. Kuhn, L. et al. Alpha-defensins in the prevention of HIV transmission among breastfed infants. J. Acquir. Immune. Defic. Syndr. 39, 138-142 (2005).

158. Bosire, R. et al. Breast milk alpha-defensins are associated with HIV type 1 RNA and CC chemokines in breast milk but not vertical HIV type 1 transmission. AIDS Res. Hum. Retroviruses 23, 198-203 (2007).

159. Bosire, R. et al. Longitudinal comparison of chemokines in breastmilk early postpartum among HIV-1-infected and uninfected Kenyan women. Breastfeed Med. 2, 129-138 (2007).

160. Walter, J. et al. Low and undetectable breast milk interleukin-7 concentrations are associated with reduced risk of postnatal HIV transmission. J. Acquir. Immune. Defic. Syndr. 46, 200-207 (2007).

161. Gray, R.H. et al. Male circumcision for HIV prevention in men in Rakai, Uganda: a randomised trial. Lancet 369, 657-666 (2007).

162. Bailey, R.C. et al. Male circumcision for HIV prevention in young men in Kisumu, Kenya: a randomised controlled trial. Lancet 369, 643-656 (2007).

163. Auvert, B. et al. Randomized, controlled intervention trial of male circumcision for reduction of HIV infection risk: the ANRS 1265 Trial. PLoS Med. 2, e298 (2005).

164. Patterson, B.K. et al. Susceptibility to human immunodeficiency virus- 1 infection of human foreskin and cervical tissue grown in explant culture. Am. J. Pathol. 161, 867-873 (2002).

165. Donoval, B.A. et al. HIV-1 target cells in foreskins of African men with varying histories of sexually transmitted infections. Am. J. Clin. Pathol. 125, 386-391 (2006).

166. McCoombe, S.G. \& Short, R.V. Potential HIV-1 target cells in the human penis. AIDS 20, 1491-1495 (2006)

167. Fischetti, L., Barry, S.M., Hope, T.J. \& Shattock, R.J. HIV-1 infection of human penile explant tissue and protection by candidate microbicides. AIDS 23, 319-328 (2009).

168. de Witte, L. et al. Langerin is a natural barrier to HIV-1 transmission by Langerhans cells. Nat. Med. 13, 367-371 (2007).

169. Rescigno, M. et al. Dendritic cells express tight junction proteins and penetrate gut epithelial monolayers to sample bacteria. Nat. Immunol. 2, 361-367 (2001)

170. Rescigno, M., Rotta, G., Valzasina, B. \& Ricciardi-Castagnoli, P. Dendritic cells shuttle microbes across gut epithelial monolayers. Immunobiology 204, 572-581 (2001).

171. Fahrbach, K.M. et al. Activated CD34-derived Langerhans cells mediate transinfection with human immunodeficiency virus. J. Virol. 81, 6858-6868 (2007).

172. Millett, G.A., Flores, S.A., Marks, G., Reed, J.B. \& Herbst, J.H. Circumcision status and risk of HIV and sexually transmitted infections among men who have sex with men: a meta-analysis. JAMA 300, 1674-1684 (2008)

173. Warner, L. et al. Male circumcision and risk of HIV infection among heterosexual African American men attending Baltimore sexually transmitted disease clinics. J. Infect. Dis. 199, 59-65 (2009).

174. Smith, S.M. et al. Topical estrogen protects against SIV vaginal transmission without evidence of systemic effect. AIDS 18, 1637-1643 (2004).

175. Pask, A.J., Mclnnes, K.J., Webb, D.R. \& Short, R.V. Topical oestrogen keratinises the human foreskin and may help prevent HIV infection. PLoS ONE 3, e2308 (2008).

176. Hladik, F. \& Hope, T.J. HIV infection of the genital mucosa in women. Curr. HIVIAIDS Rep. 6, 20-28 (2009).

177. Zapata, W. et al. Increased levels of human beta-defensins mRNA in sexually HIV-1 exposed but uninfected individuals. Curr. HIV Res. 6, 531-538 (2008)

178. Owen, S.M. et al. RC-101, a retrocyclin-1 analogue with enhanced activity against primary HIV type 1 isolates. AIDS Res. Hum. Retroviruses 20, 1157-1165 (2004). 
179. Feldblum, P.J. et al. SAWY vaginal gel (C31G) for prevention of HIV infection: a randomized controlled trial in Nigeria. PLOS ONE 3, e1474 (2008).

180. Pusch, O. et al. An anti-HIV microbicide engineered in commensal bacteria: secretion of HIV-1 fusion inhibitors by lactobacilli. AIDS 20, 1917-1922 (2006).

181. Pusch, O. et al. Bioengineering lactic acid bacteria to secrete the HIV-1 virucide cyanovirin. J. Acquir. Immune. Defic. Syndr. 40, 512-520 (2005).

182. Chancey, C.J. et al. Lactobacilli-expressed single-chain variable fragment (scFv) specific for intercellular adhesion molecule 1 (ICAM-1) blocks cell-associated HIV-1 transmission across a cervical epithelial monolayer. J. Immunol. 176, 5627-5636 (2006).

183. Tsai, C.C. et al. Cyanovirin-N inhibits AIDS virus infections in vaginal transmission models. AIDS Res. Hum. Retroviruses 20, 11-18 (2004).

184. Tsai, C.C. et al. Cyanovirin-N gel as a topical microbicide prevents rectal transmission of SHIV89.6P in macaques. AIDS Res. Hum. Retroviruses 19, 535-541 (2003).

185. Skoler-Karpoff, S. et al. Efficacy of Carraguard for prevention of HIV infection in women in South Africa: a randomised, double-blind, placebo-controlled trial. Lancet 372, 1977-1987 (2008).

186. Abdool Karim, S. et al. Safety and effectiveness of vaginal microbicides BufferGel and 0.5\% PRO 2000/5 Gel for the prevention of HIV infection in women: results of the HPTN 035 trial. In Sixteenth Conference on Retroviruses and Opportunistic Infections (Montreal, 2009).

187. Tao, W., Richards, C. \& Hamer, D. Enhancement of HIV infection by cellulose sulfate. AIDS Res. Hum. Retroviruses 24, 925-929 (2008).

188. Lederman, M.M. et al. Prevention of vaginal SHIV transmission in rhesus macaques through inhibition of CCR5. Science 306, 485-487 (2004).

189. Veazey, R.S. et al. Protection of macaques from vaginal SHIV challenge by vaginally delivered inhibitors of virus-cell fusion. Nature 438, 99-102 (2005).

190. Sugaya, M., Hartley, O., Root, M.J. \& Blauvelt, A. C34, a membrane fusion inhibitor, blocks HIV infection of langerhans cells and viral transmission to T cells. J. Invest. Dermatol. 127, 1436-1443 (2007).

191. Veazey, R.S. et al. Tropism-independent protection of macaques against vaginal transmission of three SHIVs by the HIV-1 fusion inhibitor T-1249. Proc. Natl. Acad. Sci. USA 105, 10531-10536 (2008).

192. Terrazas-Aranda, K., Van Herrewege, Y., Lewi, P.J., Van Roey, J. \& Vanham, G. In vitro pre- and post-exposure prophylaxis using HIV inhibitors as microbicides against cell-free or cell-associated HIV-1 infection. Antivir. Chem. Chemother. 18, 141-151 (2007).

193. Cranage, M. et al. Prevention of SIV rectal transmission and priming of $T$ cell responses in macaques after local pre-exposure application of tenofovir gel. PLoS Med. 5, e157; discussion e157 (2008).

194. Iqbal, S.M. \& Kaul, R. Mucosal innate immunity as a determinant of HIV susceptibility. Am. J. Reprod. Immunol. 59, 44-54 (2008). 